\title{
Citation, credit, and the ambiguous nature of creative science - a wider perspective for Bruun's views
}

\author{
David M. Wilkinson \\ David M. Wilkinson (D.M.Wilkinson@ljmu.ac.uk), Natural Science and Psychology, Liverpool John Moores \\ University, Byrom Street, Liverpool L3 3AF, UK
}

Hans Henrik Bruun (2014) argues that, although assigning credit to past work is important, it is not something that can easily be set about with formal rules-leading to charges of plagiarism if the rules are not followed to the letter. He goes further to suggest that such strict rules may actually stifle creative science and that, in this context, a much greater problem may be the large number of so-called 'original' research papers that do no more than reproduce previous findings in new settings (I have much sympathy with this last point, while noting that such studies are also crucial to the meta analysis approach to ecological questions!). Bruun (2014) develops his ideas in the context of ecological examples-here I try to provide a brief, wider context for the discussion drawing on several different areas of science from astronomy to molecular biology.

A scientist's reputation stands or falls on conceiving new ideas or collecting original data. Although there may be a considerable satisfaction in just working in an area of personal fascination irrespective of any credit (this is certainly true of many ecologists with a natural history background), credit does matter. One of the more interesting discussions of this is actually fictional - the novel The Bourbaki gambit by chemist turned novelist and playwright Carl Djerassi (1994). In the novel, a group of late career and somewhat marginalised scientists group together to have fun publishing under a single pseudonym. This scheme falls apart when they discover something truly important (in this alternative history novel, they invent PCR) and suddenly personal priority really matters! If reputation matters so much then surely a rigorous approach to citation matters too (indeed I believe it does but, as with Bruun, I don't see it as the most important thing in the long term).
There is a very practical problem with an insistence on citing the first original source-it's often completely ambiguous what you should be citing! Most ideas in science emerge over time and don't suddenly appear in the literature in their final form. The obvious example for the readership of an ecology and evolution journal being the very similar evolutionary ideas of Darwin and Wallace - which do you cite? In fact, it's more complex than that, as a trawl through the pre-1858 literature can produce many brief discussions that seem to have at least part of the idea of natural selection, and there is a huge pre-Darwinian literature on the general idea of evolution. Should you cite them all? However, Darwin's (1859) book not only introduced a range of novel theories but made them prominent. Indeed, in an interesting recent counterfactual history, Bowler (2013) suggests that without this book (i.e., if Darwin had drowned at sea in 1832), even allowing for Wallace's work, modern evolutionary ideas would have emerged much more slowly than was the case in the real $19^{\text {th }}$ Century. This would have made it even less clear who to cite-indeed if Bowler is correct, there would have been no one single person to cite as the founder of what we now call Darwinian evolution. A similar off-quoted example is the discovery of oxygen, where Carl Wilhelm Scheele, Joseph Priestly, and Antoine Lavoisier all have reasonable claims to the discovery (Bowler and Morus 2005). Returning to Darwin, he also illustrates another interesting point. While Darwin (1859) is often cited in history of science papers - such as this one-he is now seldom cited in evolutionary research papers. This is not because of any attempt by modern scientists to plagiarize his ideas, but because his ideas are now too famous to need citation (the Watson and Crick Nature paper on the structure of DNA being 
another example of something too well known for an editor or referee to insist on a citation)! So it can often (especially when there is not an obvious 'great book' such as 'On the origin of species...') be impossible to find a definitive founding document to cite, or as suggested above, sometimes things are too well known to require citation (e.g. natural selection, DNA, or PCR). Also as Bruun (2014) points out, citing some of my own history of science publications in support, we often end up citing the famous paper (or the paper by the more famous scientist) rather than the first paper-always assuming that such a document could be unambiguously identified. Indeed, this citing of the most well-known source is such a common practice it has its own term to describe it, the 'Matthew Effect' (from Matthew 25:29 'For unto every one that hath shall be given': see Merton 1968). Note also that I have just assumed that the Bible is so well known I don't need to formally cite it in the last sentence.

It is clear from the work of historians that a strict adherence to what we rightly think of as good practice is not required for world class science. For example, the astronomer Fred Hoyle would certainly have fallen foul of ridged strictures on citing previous workers. Indeed, as one of his biographers pointed out an 'enduring criticism of Hoyle's scientific papers has been his failure to acknowledge the work of others' (Mitton, 2005: 151); and yet he was certainly a theoretician with the 'inspiration' of which Bruun (and I) approve. A slightly different example is the rigour, or lack thereof, with which some scientists have tried to falsify their key results - often overlooking data that looked bad for their ideas. Robert Millikan's selective use of his experimental results when calculating the charge on the electron are well known, as is the rather ambiguous nature of the observational data that Arthur Eddington used to test Einstein's ideas on general relativity (Waller 2002). In both cases, this later looked like good judgment on their part, but only because they turned out to be largely right!

Perhaps the only lesson to be drawn is that doing creative science is a difficult and messy process-one can broadly specify good practice but attempts to codify it in detail will likely fail and we should probably not try too hard, for fear of constraining what Bruun calls 'inspiration'.

\section{References}

Bowler, P.J. 2013. Darwin deleted. University of Chicago Press, Chicago. CrossRef

Bowler, P.J. and Morus, I.R. 2005. Making modern Science. The University of Chicago Press, Chicago. CrossRef

Bruun, H.H. 2014. Zero tolerance to plagiarism will kill inspiration: a critique for academic meritocracy. Ideas in Ecology and Evolution 7:34-37. CrossRef

Darwin, C. 1859. On the origin of species by means of natural selection. John Murray, London.

Djerassi, C. 1994. The Bourbaki gambit. University Georgia Press, Georgia.

Merton, R.K. 1968. The Matthew Effect in science. Science 159, 56-63. CrossRef

Mitton, S. 2005. Fred Hoyle, a life in science. Aurum Press, London.

Waller, J. 2002. Fabulous Science. Oxford University Press, Oxford. 